\title{
La infrarrepresentación de los medios de comunicación hacia el deporte femenino llega a las redes sociales. Estudio de casos en Instagram
}

The underrepresentation of the media towards women's sport reaches social media. Case study on Instagram

\author{
Álvaro Galván Cárdenas \\ Universidad de Sevilla \\ alvarogalvancardenas@gmail.com
}

\section{Palabras clave}

- Redes Sociales

- Deporte Femenino

- Mujeres Deportistas

- Medios de

Comunicación

- Instagram

\section{Resumen}

El deporte femenino ha ido ganando terreno con el paso de los años; sin embargo, en el ámbito de los medios de comunicación, todavía queda un largo camino por recorrer, incluidas aquí las redes sociales de las que los profesionales de la información se valen para la difusión de contenidos. Tomando como objeto de estudio los diarios Marca, As, Mundo Deportivo y Sport (los cuatro con mayor audiencia en España) se indaga durante un periodo de año y medio (enero de 2020 - junio de 2021) las publicaciones de sus cuentas de Instagram que involucran a mujeres y al deporte practicado por ellas, observando diversos parámetros que las envuelven para determinar la calidad de estos contenidos, además de cuantificarlos con respecto al total de publicaciones. Con este trabajo se pretende ilustrar que las deportistas continúan estando infrarrepresentadas en el ámbito de las redes sociales propiedad de los medios de comunicación, añadiendo ante ello una serie de recomendaciones, ante todo, aumentar el número de investigaciones de este tipo en favor de la visibilización y la igualdad en el deporte. 


\section{Key words \\ - Social Media \\ - Women's sports \\ - sportswomen \\ - Media \\ - Instagram}

\begin{abstract}
Women's sport has gained ground over the years; However, in the field of communication media, there is still a long way to go, including the social media that information professionals use to broadcast their content. Taking as an object of study the newspapers Marca, As, Mundo Deportivo and sport (the four with the highest audience in Spain), during a period of a year and a half (January 2020 - June 2021), we analyse their Instagram accounts and the publications that involve women and the sport practiced by them, observing some parameters that determine the quality of these contents, in addition to quantifying them with respect to the total number of publications. This work is intended to illustrate that female athletes continue to be underrepresented in the field of social media owned by the media, adding a series of recommendations, above all, increasing the number of investigations of this type in favour of visibility and equality in sport.
\end{abstract}

\section{Introducción}

\subsection{Contextualización de la infrarrepresentación del deporte femenino}

Muchos estudios han abordado el tema de la infrarrepresentación y la estereotipación del deporte femenino en los medios de comunicación. Siendo estos portavoces de la actualidad informativa y creadores de la opinión pública, llega a la sociedad una imagen de las mujeres deportistas que, en muchas ocasiones, no se corresponde con la realidad. Se forma así un círculo vicioso que nos lleva a preguntarnos y a debatir sobre si el problema de esta escasa cobertura se encuentra en la audiencia, que no demanda contenidos en el que las mujeres son las protagonistas de la información deportiva, o en los medios, que no ofrecen las noticias desde una perspectiva objetiva y en igualdad de condiciones que aquellas que protagonizan los hombres.

Desde finales del siglo pasado, las mujeres han visto mejorada su posición en el ámbito del deporte, lo cual ha propiciado un auge en comparación con épocas precedentes (Romero de la Marta 2019, 6). Sin embargo, pese al avance experimentado, "el deporte se ha mantenido como un espacio construido, practicado, disfrutado y regulado mayoritariamente por los hombres", permaneciendo en la cultura social la idea de un modelo de hegemonía masculina (Gonzáles Pagés y Fernández González 2009, 128).

En el caso de España, las mujeres siempre han tratado de legitimar su propio espacio en el ámbito deportivo, combatiendo la idea de que es un espacio meramente masculino, en el marco de las reivindicaciones feministas (Dunning 2003, 271). Una muestra de ello es la notable evolución de las deportistas españolas en el marco de los Juegos Olímpicos. De hecho, en las dos últimas citas, las mujeres obtuvieron más del doble de los logros que España aportó al medallero nacional (12 de 18, en Londres 2012; y 9 de 17, en Río 2016).

Resulta irónico por tanto presenciar cómo los medios de comunicación han retrocedido en lo que a información deportiva se refiere, demostrando una escasa cobertura y presencia del deporte femenino que no corresponde con la realidad (Sainz de Baranda Andújar 2013, 186). Alfaro Gandarillas, Bengoechea Bartolomé y Vázquez Gómez $(2010,8)$ señalan dos causas que propician la infrarrepresentación mediática de las mujeres deportistas. Una de ellas, como ya hemos adelantado, es que el modelo deportivo fue construido bajo una hegemonía masculina, sin considerar necesaria femenina. La otra causa tiene que ver con la permanencia de estereotipos sociales de género, difundidos a través de los medios de comunicación. Esto conforma un círculo vicioso al considerarse estos medios un elemento fundamental en la formación de opinión (Fraga Medín 2007, 45).

Centrándonos en este último asunto, López Albalá $(2016,107)$ afirma que, efectivamente, los medios de comunicación de masas ofrecen una información especialmente estereotipada del deporte femenino y "con tendencia a una importante discriminación sexual, si bien más refinada que en épocas anteriores". 


\subsection{Las redes sociales como nuevos canales de comunicación en el deporte}

Con todo lo anterior, observamos cómo tanto el deporte femenino como los medios de comunicación juegan un papel importante en la actualidad, protagonizando ambos una relación marcada por la desigualdad, en la que la prensa continúa, en pleno siglo $X X I$, sin otorgar a las mujeres deportistas el papel que verdaderamente merecen por sus méritos y logros.

Ante esta situación, aparece en contexto las redes sociales, entendiéndose estas como elementos de la sociedad actual capaces de reflejar la realidad (o una versión de ella). Sus datos son de verdadera importancia en el análisis del deporte femenino en este ámbito. Sin embargo, cabe hacer una distinción importante que marcará nuestro estudio. Por un lado, conscientes de su infrarrepresentación en medios tradicionales y en línea, las atletas femeninas consideran las redes sociales como una herramienta potencial para corregir esa falta de cobertura, e incluso cuestionar y reelaborar las identidades normativas de género (Toffoletti y Thorpe 2018, 28). En cambio, los medios, empleando también estas redes sociales, continúan sin contribuir a la igualdad a través de estos nuevos canales de comunicación digitales. La discriminación de género y la estereotipación de las mujeres deportistas siguen estando a la orden del día en estas nuevas tecnologías, en las que los medios de comunicación de masas también tienen presencia (Adá Lameiras 2019, 43).

Volvemos a hacer referencia a Toffoletti y Thorpe $(2018,13)$ para destacar una idea sustentada en esa escasa cobertura mediática que reciben las mujeres en los medios de comunicación. Y es que las deportistas usan las redes sociales para proyectarse como agentes empoderadas que participan activamente en la creación y realización de sus propias identidades.

Por su parte, Layton $(2020,12)$, que profundiza más sobre la evolución e importancia de las redes sociales en un ámbito como el deporte, señala que en ellas se ha vivido desde comienzos de siglo una migración informativa, por la que deportistas, clubes y federaciones ya no dependen tanto de los medios. Es decir, las deportistas han dejado de estar tan sometidas a lo que de ellas se pronuncie en los medios, pues ahora también son dueñas de la información a través de las redes; en concreto, de sus propios perfiles personales.

Pero aunque estas deportistas no se encuentren tan sometidas a la agenda temática que marquen los medios de comunicación, sus informaciones estereotipadas han llegado también a las redes sociales, como comentábamos anteriormente. En un mundo hiperconectado y globalizado como en el que vivi- mos, esta presencia se traduce en una mayor difusión de sus contenidos y que esta realidad distorsionada sobre las deportistas llegue a más gente.

\section{La infrarrepresentación y estereotipación del deporte femenino}

La obtención de un tratamiento igualitario en los medios entre hombres y mujeres aún queda lejana. Basta con mirar las noticias deportivas de un periódico o televisión. ¿Cuántas deportistas aparecen protagonizándola? En caso de que aparezcan, ¿cómo se muestra a estas mujeres? Y, ¿cuenta la noticia con calidad informativa?

Lo primero en tener en cuenta es que, adoptando los medios un sesgo masculino en la representación de la información, las mujeres atletas y los deportes femeninos aparecen en menor número de ocasiones y con una cobertura de menor calidad que los deportes y deportistas masculinos (Toffoletti y Thorpe 2018, 13). Esta escasa representación refuerza la idea de que las mujeres tienen menos interés por el ejercicio físico (al contrario que los hombres) perpetuando esa inferioridad atlética femenina.

Por otra parte, lo habitual en la prensa deportiva española es que se ponga el foco en las mujeres deportistas cuando participan en algún evento importante y salen victoriosas. Por lo demás, para que un suceso relacionado con el deporte femenino llegue a ser noticia debe albergar algún contenido morboso o con controversia, por el que la atleta suele ser juzgada (Fernández Carretero 2018, 37).

Se sobrentiende que, durante la celebración de unos Juegos Olímpicos, Campeonatos del Mundo o de Europa, los medios ofrecerán una información de carácter más objetivo, poniendo atención en el logro de la deportista. Sin embargo, se trata de un hecho aislado que no debe esconder la realidad. Y es que, por lo general, deporte femenino se convierte en noticioso cuando se destacan atributos estéticos, sexuales y personales de las atletas.

A partir de la anterior afirmación, López Díez (2011) establece una clasificación detallada sobre los estereotipos de género que los medios construyen y reproducen: 1) De belleza (si la deportista encaja en el ideal masculino, se presenta como objeto sexual de deseo, sin importar su carrera profesional). 2) Referencias sexistas (se destacan aspectos de la deportista que nada tienen que ver con su profesión, por ejemplo sus atributos físicos, para ser objeto de atención informativa). 3) Estatus vicario y referencias a la vida personal y familiar (se presenta a la mujer de manera estereotipada, según los cánones tradi- 
cionales, como esposa, novia o madre). 4) Asignación de roles de género (Además de al deporte, se centra la atención en la alimentación, vestimenta, higiene y otras muchas actividades de la deportistas; mientras que en los hombres lo único que se tiene en consideración es la práctica deportiva). 5) Control de las emociones (no es deseable que las mujeres desarrollasen rasgos que no sean asociados convencionalmente con la feminidad). Diferenciar deportes masculinos y femeninos (a las mujeres se las relaciona con deportes más delicados, sencillos y armónicos, evitando ellas mismas desde jóvenes involucrarse en prácticas más masculinas para que no las definan con términos como "marimacho" o "lesbiana"). 6) Lenguaje sexista (deportistas definidas con adjetivos, diminutivos y frases condescendientes).

Por lo tanto, pese al proceso de desmitificación que las mujeres han vivido desde finales del siglo XX, observamos una situación en la que las deportistas son privadas de su legitimidad por los medios de comunicación, a través de la sexualización y la hegemonía masculina.

\section{Estudio de casos en redes sociales}

En base a lo expuesto en el apartado anterior, desarrollamos ahora una breve investigación para corroborar la infrarrepresentación del deporte feme- nino en las redes sociales de los medios de comunicación. Aportamos así una perspectiva más actual y diversa, teniendo en cuenta los numerosos análisis sobre diferentes medios (periódicos y televisiones, mayoritariamente), que ya existen.

consideramos que estos nuevos canales de comunicación digital siguen una línea de actuación similar a la de los medios. Es decir, que sus perfiles de redes sociales emiten una cobertura escasa y un tratamiento estereotipado de las deportistas, al igual que en sus páginas, retransmisiones y/o páginas web. Es este el aspecto en el que ahondaremos, en las estrategias y prácticas mediáticas que los medios emplean en sus cuentas oficiales. De forma más específica, vamos a centrar nuestro análisis en Instagram, donde tanto el texto de la publicación como la imagen en sí nos darán pruebas de si se ha emitido algún tipo de mensaje estereotipado; además de contabilizar las publicaciones sobre deporte femenino que existe. Asimismo, el número de comentarios y 'me gusta' nos darán una idea del impacto social generado, pudiéndose comparar este con publicaciones similares emitidas desde las propias deportistas, quienes sí emplean sus perfiles de redes sociales para darse la cobertura que merecen y contribuir a la igualdad. Por lo tanto, y resumiendo lo anterior, analizaremos las publicaciones de Instagram de los principales medios deportivos de España, según el EGM: Marca, As, Mundo Deportivo y Sport.

\section{Imagen 1: Comparación entre lectores diarios en papel y seguidores en Instagram}

\begin{tabular}{|l|c|c|}
\cline { 2 - 3 } \multicolumn{1}{c|}{} & Lectores diarios en papel & Seguidores en Instagram \\
\hline Marca & 849.000 & 2.800 .000 \\
\hline As & 378.000 & 932.000 \\
\hline Mundo Deportivo & 234.000 & 1.900 .000 \\
\hline Sport & 174.000 & 1.400 .000 \\
\hline
\end{tabular}

Fuente: EGM (II Ola de 2021) / Elaboración propia

Previamente, a modo de contexto, conviene señalar Instagram como una red social cuya función principal es "compartir fotos y videos mediante el uso de teléfonos inteligentes, tabletas y computadoras personales", dando además a sus usuarios la opción de "tomar fotografías y filmar videos de hasta 60 segundos, editarlos y publicarlos, con la opción de replicarlos en otras redes sociales" (Lavalle 2017, 10). La cultura que impera actualmente en la sociedad es eminentemente visual. Por eso, ante cualquier hecho o acontecimiento que llega a su fin, "la fotografía aún existirá, confiriéndole una especie de inmortalidad (e importancia) de la que jamás habría gozado de otra manera", existiendo y perdurando así para los restos (Sontag 1977, 26). 
Afirmaciones como la anterior son en las que se respaldan Lirola Pino, Martín Perales y Martín Pueyo para explicar el éxito absoluto que cada vez más va logrando Instagram en los últimos años $(2015,16)$. Y es que "Instagram ha crecido de manera constante desde su lanzamiento", demostrándose su expansión en que, en todo el mundo "totaliza 1.08 mil millones de usuarios activos mensuales, colocándolo en el tercer lugar detrás de Facebook, YouTube y WeChat" (Morales 2021, s. p.). Además, aunque el nacimiento de Instagram data del año 2010, esta plataforma ha sabido mantener su esencia. No obstante, sus actualizaciones y pequeños cambios han logrado cambiar el significado de las redes sociales "y abre una ventana a nuevas formas de conectividad e incluso brinda la oportunidad de potenciar a ciertas profesiones, entre ellas, el periodismo digital" (Bohórquez León 2020, 33).

Así pues, aprovechando los medios esa capacidad de Instagram para crear contenidos e interactuar con el público, "los periodistas están enganchados a sus teléfonos móviles para capturar cualquier tipo de información que pueda ser útil" (De la Rosa Mendoza 2018, 20). De esta manera, como ya se indicó anteriormente, se ha ido estableciendo una conexión entre las redes sociales y el periodismo digital (Carretero 2014, s. p.).

Por lo tanto, se trata este de un análisis que podría ser desarrollado desde que las cuentas fuesen creadas hasta la actualidad. Sin embargo, teniendo en cuenta las limitaciones temporales que supondría hacer 'scroll' en perfiles con una gran cantidad de publicaciones, nuestro análisis se centrará en el último año y medio. Es decir, desde enero de 2020 hasta junio de 2021 (incluido). En ese intervalo temporal se estudiarán las publicaciones que hagan referencia a mujeres deportistas. Además, se llevará la cuenta del número de publicaciones emitidas desde entonces, para calcular el porcentaje de noticias sobre deporte femenino.

En las publicaciones que sean de nuestro interés nos fijaremos en el tipo de discurso que emplea el medio (si esta estereotipado o no, si hay una discriminación oculta, si muestra una imagen que resalte los atributos físicos de la mujer, si se emplean pocos caracteres en el texto...). Es decir, los resultados de esta variable se obtienen a partir de un análisis cuantitativo sobre el total de publicaciones de estos cuatro medios en el período seleccionado, tanto en las que aparecen mujeres como en las que se muestran hombres.

Con los resultados que se obtengan, se observará si ha habido algún aumento en el número de publicaciones sobre deporte femenino, qué lo ha propiciado, cuántas noticias protagonizadas por mujeres se publican en un año natural, qué tratamiento reciben, cómo son expuestas y cómo las reciben la audiencia.

Asimismo, cabe destacar los parámetros del análisis de contenido que se han empleado para el estudio de las cuentas de Instagram de los cuatros medios de comunicación en los que se centra esta investigación. Estos se refieren a información general, disciplina, área de referencia y carácter de la publicación. Dentro de la categoría de información general se encuentran dos variables: frecuencia (es decir, con qué asiduidad aparecen post relacionados con las mujeres y el deporte femenino) y nombres propios (quienes protagonizan la publicación). En la categoría de disciplina se enmarca el deporte (o deportes) al que se haga referencia en el post, pudiendo observar cuáles son los más frecuentes en los que se enmarcan a las mujeres. Por su parte, el apartado de área de referencia se refiere a la nacionalidad de las protagonistas o el lugar en el que se desarrolla el deporte al que se hace referencia en la publicación, siendo esta una forma de observar el trato que se le dan a contenidos nacionales o internacionales. Mientras que, en la categoría de carácter de la publicación se engloba todo lo relativo al lenguaje, rol que toma la mujer o cómo está expuesta en la imagen del post.

Tras realizarse una codificación y una comprobación de la totalidad de la muestra, (es decir, sumando los post relativos al deporte femenino en los cuatro perfiles de Instagram), vemos que esta se compone de 471 unidades formadas por fotografías y vídeos, extraídas de una población (publicaciones totales dentro de la horquilla temporal a analizar) de 24.586 unidades. 


\section{Imagen 2: Publicaciones que involucran a mujeres y hombres en cada medio}

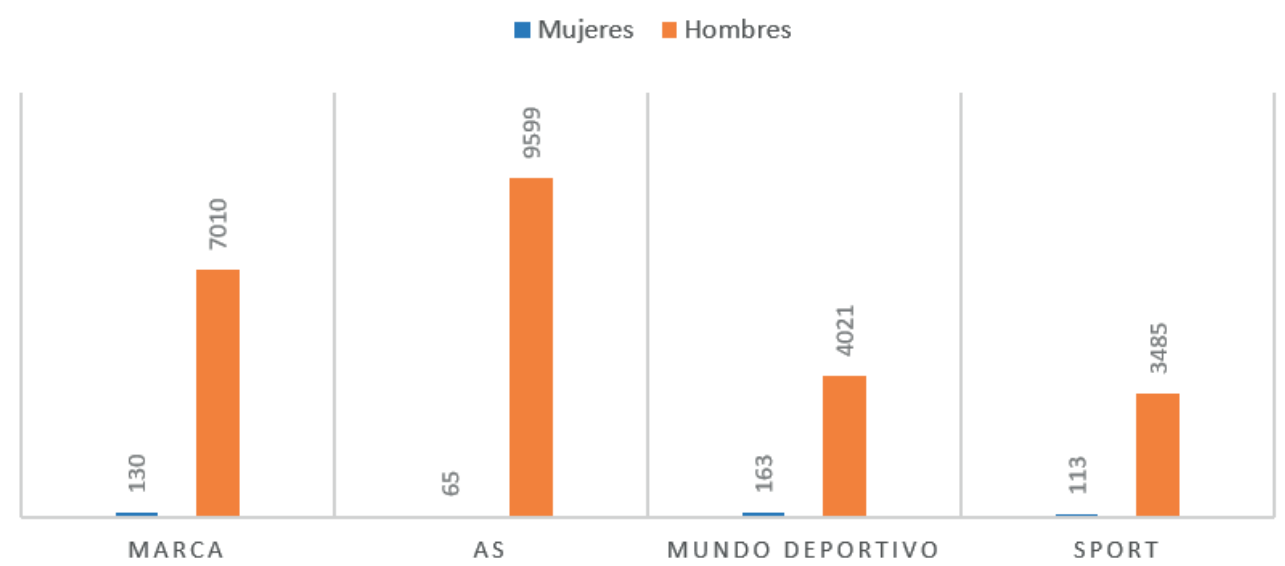

Fuente: Instagram / Elaboración propia

\subsection{Marca}

El nacimiento de Marca data del año 1938, en forma de semanario en la ciudad de San Sebastián, y no fue hasta 1942, tras la Guerra Civil, cuando su tirada se convirtió en diaria y trasladó su sede a Madrid. Bajo el amparo del grupo Unidad Editorial, la misión de este diario no ha sido otra que la de ofrecer contenidos deportivos, especialmente, de fútbol. No obstante, su localización Ileva a identificar este diario con los equipos madrileños, en concreto con el Real Madrid, pero "nunca se ha despreocupado de los clubes de otras provincias y, en menor medida, de los deportes minoritarios" (Sainz de Baranda Andújar 2014, 111).

Fue en el año 2010 cuando Marca comenzó a tener presencia en redes sociales (García Noé 2016, 20), llegando a Instagram el 29 de septiembre de 2015. Finalizado el primer semestre de 2021, su cuenta oficial en esta plataforma cuenta con 2.800 .000 seguidores.

Entre el 01 de enero de 2020 y el 30 de junio de 2021, el diario Marca publicó un total de 7.140 post en Instagram, de los cuales, 130 involucraban a las mujeres y al deporte femenino, es decir, tan solo un 1,82\% del total. Asimismo, observando la Imagen 4, los picos más altos de publicaciones dedicadas al deporte femenino se encuentran en marzo de 2020, con post sobre mujeres deportistas que animaban a público a quedarse en casa durante la pandemia por coronavirus, y en noviembre de 2020, durante la celebración del MARCA Sport Weekend, un evento organizado por el propio diario.

\section{Imagen 3: Publicaciones de Marca en Instagram que involucran a mujeres y hombres durante el periodo analizado}

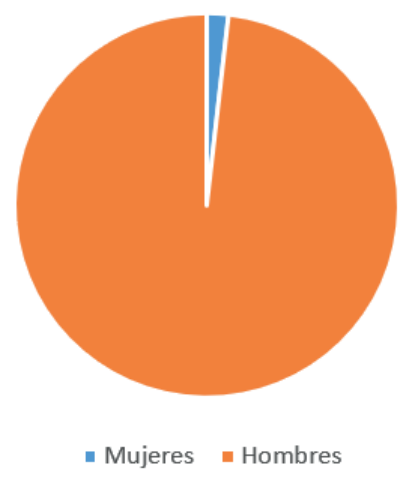

Fuente: Instagram / Elaboración propia 


\section{Imagen 4: Reparto de publicaciones en Instagram sobre deporte femenino por fecha en Marca}

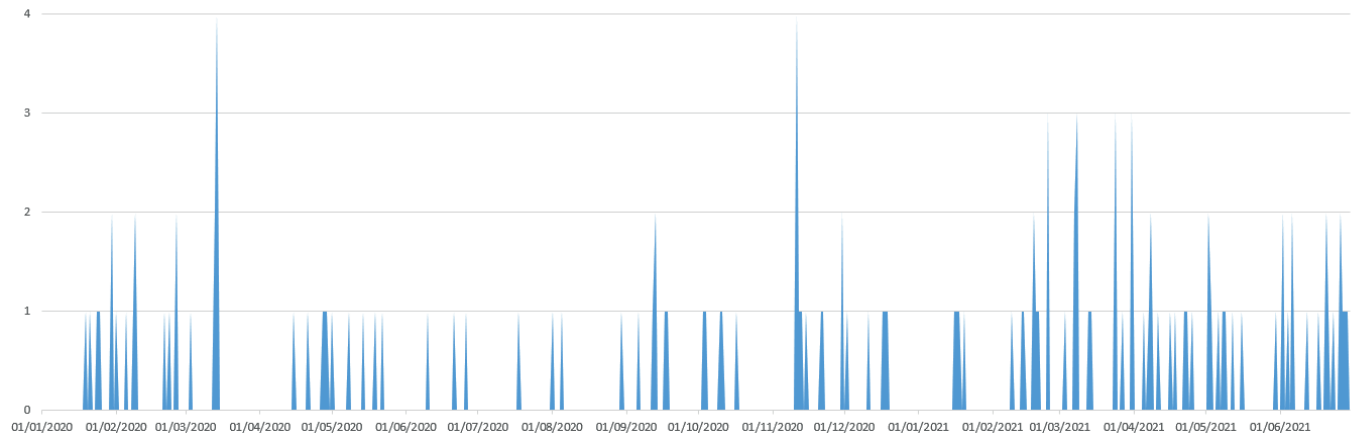

Fuente: Instagram / Elaboración propia

Haciendo una distinción por deportes, destaca la gran variedad de disciplinas practicadas por mujeres en los que Marca centra su atención. Así, de esas 130 publicaciones sobre deporte femenino, un 70,77 \% hacían referencia a un deporte que no fuese el fútbol, mientras que el porcentaje del llamado 'deporte rey' (29,23\%) se centra ante todo en el ámbito nacional, focalizando en clubes como el Barcelona
Femenino, Real Madrid Femenino, Atlético de Madrid Femenino y la Selección española femenina. En total, los post de Marca que involucran a mujeres en el espacio temporal detallado hacen referencia a un total de 24 disciplinas, además de otra serie de publicaciones enmarcadas dentro del ámbito publicitario o de organizaciones como el Consejo Superior de Deportes

\section{Imagen 5: Disciplinas a las que hacen referencia las publicaciones sobre deporte femenino en Marca}

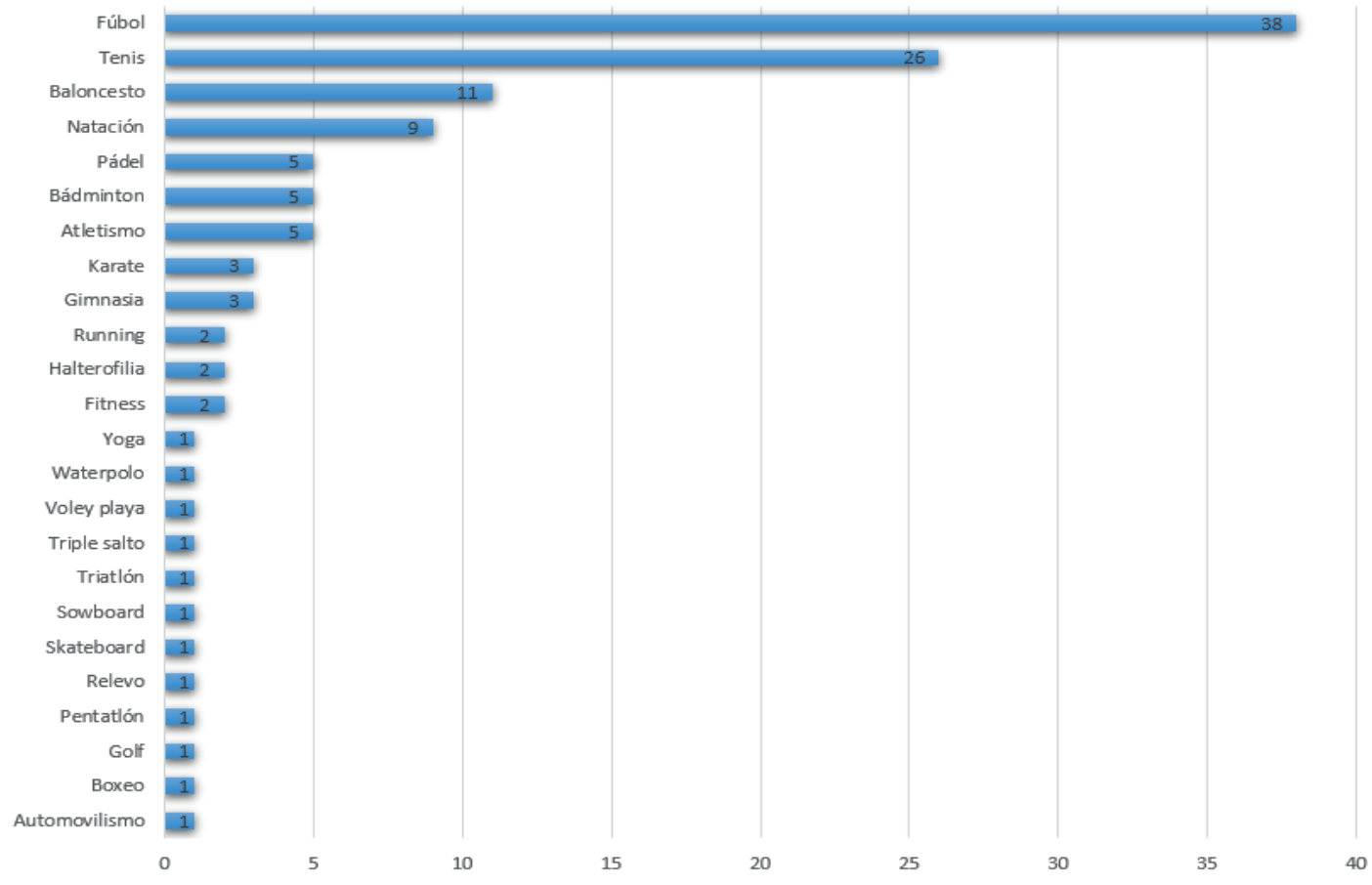

Fuente: Instagram / Elaboración propia 
Al ser un medio nacional, el área de referencia de Marca está también vinculado al deporte femenino español y a las deportistas nacionales. Aun así, en el $26,92 \%$ de las publicaciones que involucran a mujeres, las protagonistas son deportistas extranjeras, sin vinculación a ningún club o entidad de nuestro país, destacadas por haber recibido algún galardón o por haber emitido algún contenido viral. Más frecuentes son en cambio las alusiones a deportistas españolas, equipos o selecciones nacionales.

\section{Imagen 6: Área de referencia de las publicaciones sobre deporte femenino en Marca}

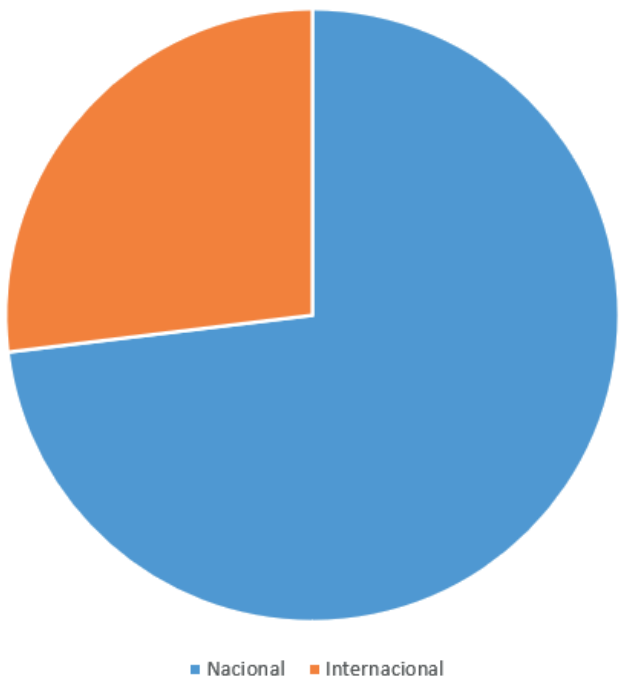

Fuente: Instagram / Elaboración propia

Por último, sobre el carácter de las publicaciones sobre deporte femenino emitidas por Marca en Instagram, tan solo en el 57,69\% de los casos los contenidos son meramente deportivo; es decir, que todo lo que engloba al post (lenguaje, rol de la mujer o imagen) tiene una finalidad informativa sobre el deporte en cuestión. Sin embargo, cabe señalar que, en este período de año y medio, Marca tan solo ha realizado un total de siete entrevistas sobre deporte femenino: Carolina Marín (balonmano), Teresa Perales (natación), Lucía Sainz y Gemma Triay (pádel), Lili Fernández y Elsa Baquerizo (vóley playa), Marta Ortega (pádel), las gemelas Esther y Gemma Pin (fitness) y Mireia Belmonte (natación). Sobre el carácter del resto de publicaciones, destacan un 11,54\% de contenidos virales sobre deporte femenino y un $10,77 \%$ referente a diversas entregas de premios.

\section{Imagen 7: Carácter de las publicaciones sobre deporte femenino en Marca}

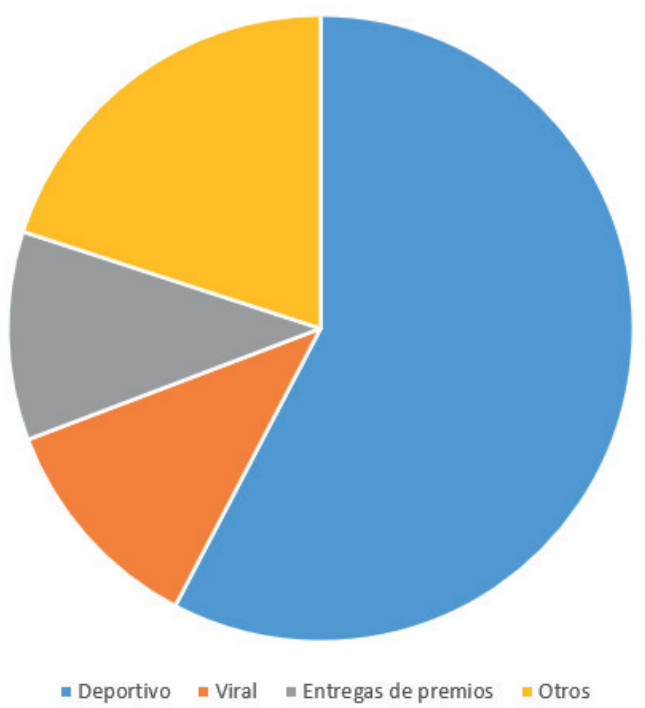

Fuente: Instagram / Elaboración propia

\subsection{As}

El primer número de As apareció en 1967 y, desde su nacimiento, tuvo una periodicidad diaria para poder competir con Marca. “Desde el principio apostó por el fútbol, por los equipos madrileños, pero no descuidó otros deportes como baloncesto, motor, boxeo, atletismo o tenis" (Sainz de Baranda Andújar 2014, 111). Tal y como señala la autora, en la actualidad, siendo propiedad del Grupo PRISA, el diario As "sigue centrándose en el fútbol dando especial cobertura a los equipos madrileños de mayor tradición, Real Madrid y Atlético de Madrid, pero también informa sobre otras disciplinas deportivas" $(2014,112)$. En este caso, la llegada de As a Instagram se dio el 4 de diciembre de 2014 y, al final del primer semestre de 2021, este perfil cuenta con 932.000 seguidores, siendo la cifra más baja de los cuatro medios analizados en este estudio.

Entre el 01 de enero de 2020 y el 30 de junio de 2021, el diario As publicó un total de 9.664 post en Instagram, de los cuales, 65 involucraban a las mujeres y al deporte femenino, es decir, tan solo un 0,67\% del total, siendo el porcentaje más bajo de entre los cuatro medios analizados. Observando la Imagen 9, los picos más altos de contenidos sobre deporte femenino se encuentran a finales del año 2020, en el mes de diciembre, debido a la celebración de los Premios AS y la gala 'The Best'. 


\section{Imagen 8: Publicaciones de As en Instagram que involucran a mujeres y hombres durante el periodo analizado}

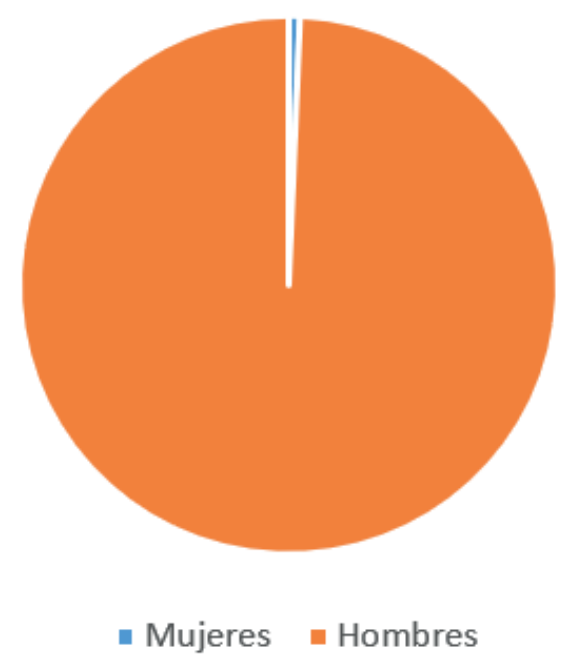

Fuente: Instagram / Elaboración propia

Imagen 9: Reparto de publicaciones en Instagram sobre deporte femenino por fecha en As

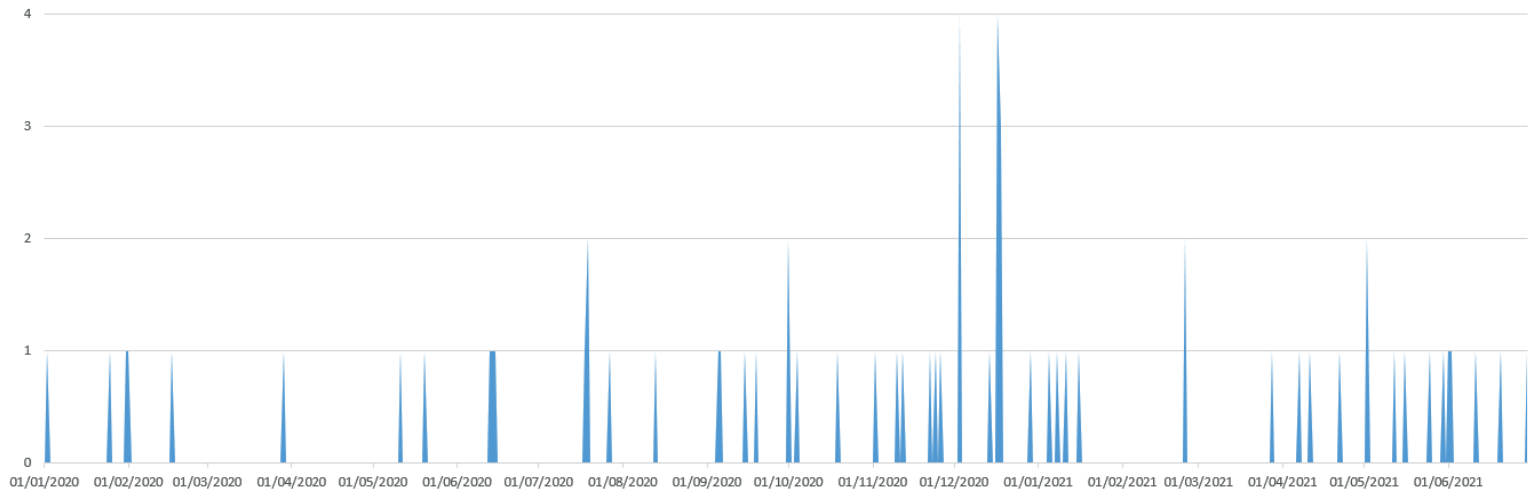

Fuente: Instagram / Elaboración propia

Distinguiendo por disciplinas, de las 65 publicaciones sobre deporte femenino extraídas entre enero de 2020 y junio de 2021 , el 61,53\% de ellas hace referencia a deportes que no son fútbol, destacando entre estos el tenis y el baloncesto. Por lo tanto, se observa una gran variedad de disciplinas (16 en total) en po- cos contenidos sobre DF, aunque son escasos también los que contienen un carácter deportivo, como ya se comprobará posteriormente. Además, otra serie de publicaciones quedan enmarcadas dentro del ámbito de organizaciones como el Consejo Superior de Deportes. 
Imagen 10: Disciplinas a las que hacen referencia las publicaciones sobre deporte femenino en As

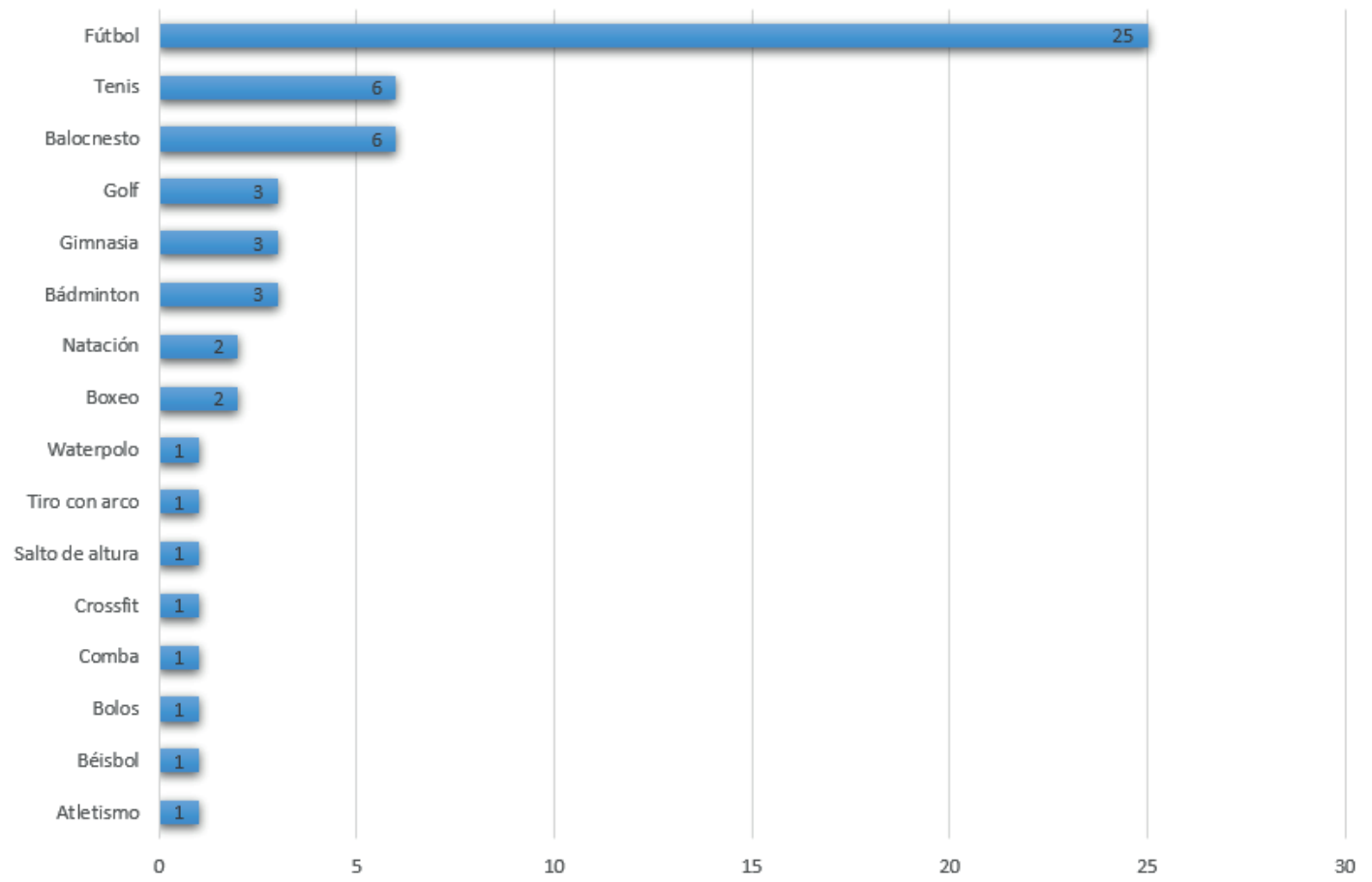

Fuente: Instagram / Elaboración propia

Al igual que ocurre con Marca, al ser As un medio nacional, su área de referencia se vincula al deporte femenino español y a las deportistas nacionales. Aun así, un considerable porcentaje de publicaciones (el $41,54 \%)$, las protagonistas son deportistas extranje- ras, sin vinculación a ningún club español. Por lo tanto, en comparación con el anterior diario, As ofrece una perspectiva más amplia, que traspasa nuestras fronteras, dentro de la escasez de post relacionados con el deporte femenino.

\section{Imagen 11: Área de referencia de las publicaciones sobre deporte femenino en As}

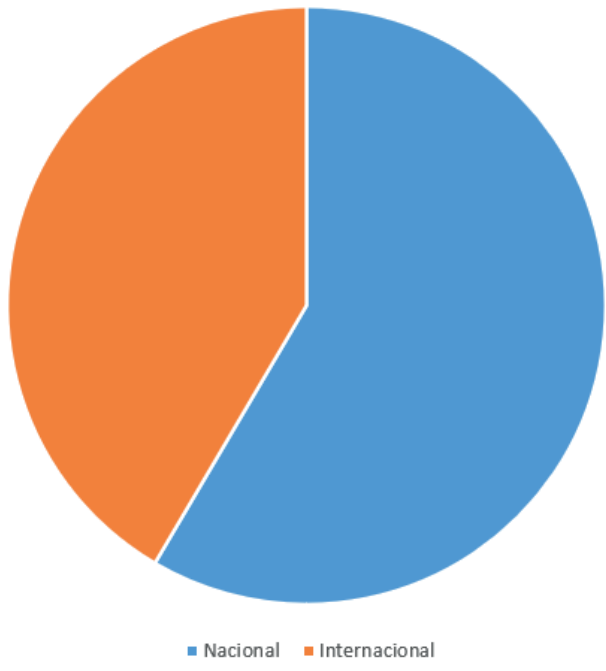

Fuente: Instagram / Elaboración propia 
Por último, sobre el carácter de la publicaciones sobre deporte femenino emitidas por As en Instagram, en menos de la mitad de los casos (44,62\%) los contenidos son meramente deportivo. Es más, este diario tan solo realizó una entrevista propia sobre deporte femenino en año y medio (a la futbolista Laura Rodríguez, de la UDS Salamanca). Aparte, sobre el carácter del resto de publicaciones, destacan también un $21,54 \%$ de contenidos referentes a diversas entregas de premios y un 18,46\% de publicaciones virales protagonizadas por mujeres.

\section{Imagen 12: Carácter de las publicaciones sobre deporte femenino en As}

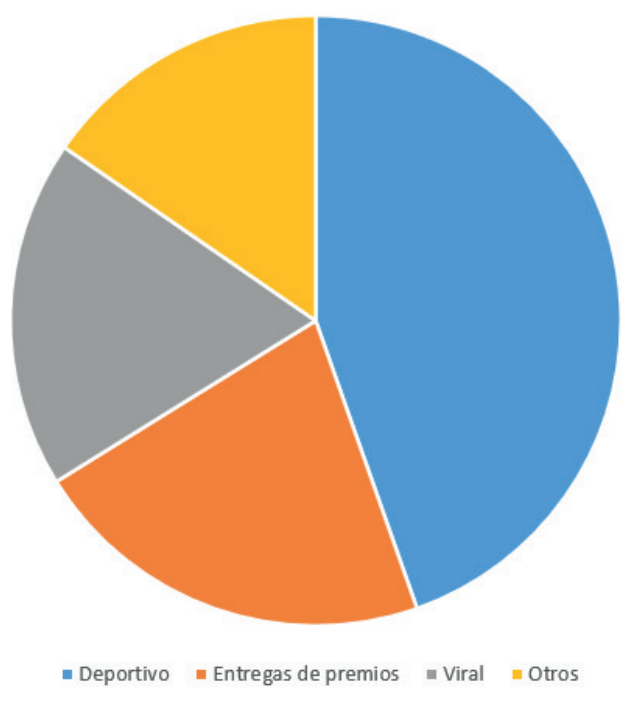

Fuente: Instagram / Elaboración propia

\subsection{Mundo Deportivo}

“Fundada en febrero de 1906, Mundo Deportivo es la publicación deportiva más antigua de España y la segunda de Europa, solo por detrás de La Gazzetta dello Sport" (García Noé 2016, 20). En sus inicio su publicación fue semanal, luego bisemanal, trimestral y cuadrisemanal hasta que en 1929 pasó a ser diaria (Sainz de Baranda Andújar 2014, 109). Cabe destacar que Mundo Deportivo, con sede en Barcelona y pro- piedad del grupo Godó, es el único diario deportivo español nacido a principios del siglo XX que sobrevive $y$, tal y como señala esta autora, "se centra en diferentes deportes, según la tendencia del momento", siendo el fútbol el más relevante, aunque también da buena información sobre el resto de disciplinas (2014, 109). La llegada de Mundo Deportivo a Instagram se dio el 21 de marzo de 2013, contando al finalizar el primer semestre de 2021 con un total de 1.900.000 seguidores.

Entre el 01 de enero de 2020 y el 30 de junio de 2021, Mundo Deportivo emitió un total de 4.184 publicaciones en Instagram, de las cuales, 163 involucraban a las mujeres y al deporte femenino. Es decir, tan solo un 3,9\% del total, el cual alcanzó su mayor pico en mayo de 2021, como se observa en la Imagen 14, debido a la consecución del triplete (Liga, Copa de la Reina y Champions Legaue) por parte del FC BarceIona Femenino.

\section{Imagen 13: Publicaciones de Mundo Deportivo en Instagram que involucran a mujeres y hom- bres durante el periodo analizado}

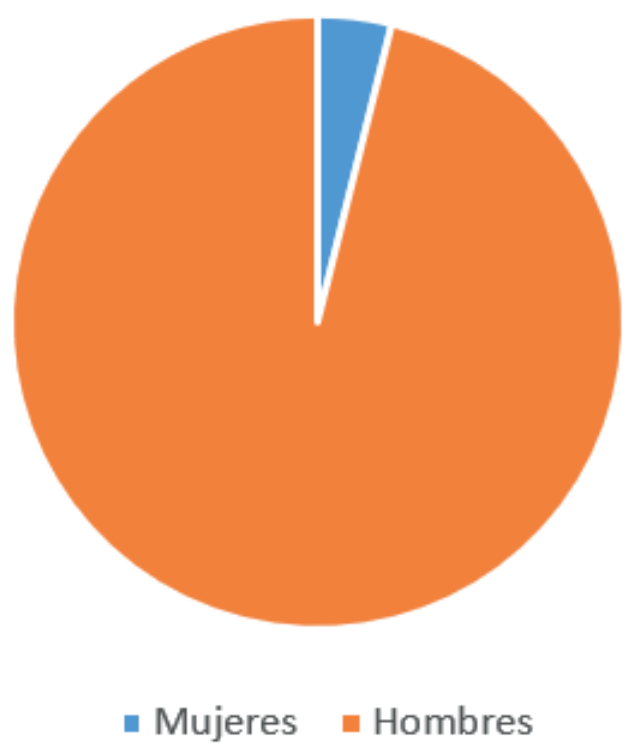

Fuente: Instagram / Elaboración propia 


\section{Imagen 14: Reparto de publicaciones en Instagram sobre deporte femenino por fecha en Mundo Deportivo}

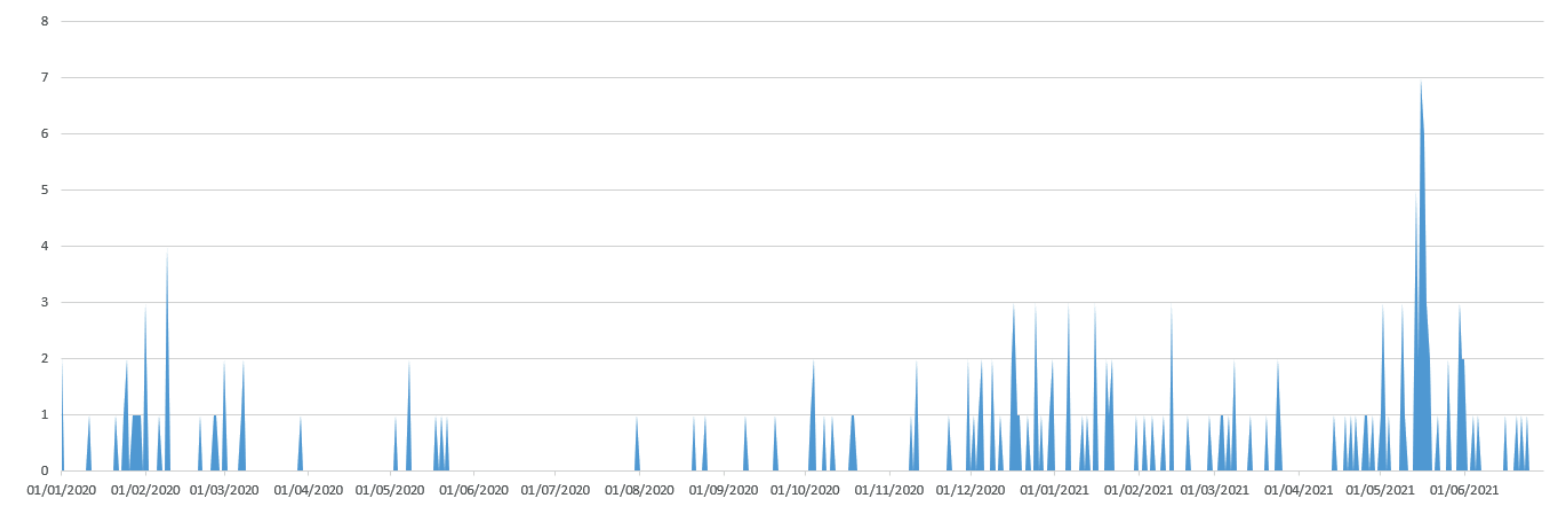

Fuente: Instagram / Elaboración propia

Al tener su sede en Barcelona, Mundo Deportivo centra sobre todo sus noticias en el deporte catalán y, en mayor medida al fútbol y al FC Barcelona. Por ello, al hacer una distinción por disciplinas, tan solo un $14,72 \%$ de las publicaciones analizadas hacen referencia a un deporte que no sea el fútbol, observando eso sí una mayor variedad de discipli- nas que en sport, como se comprobará posteriormente.

Dentro de las 139 publicaciones (de un total de 163) dedicadas al fútbol, en 109 se hace referencia a la sección femenina del FC Barcelona o a alguna de sus jugadoras, que registraron en la 2020-21 la mejor temporada de su historia.

\section{Imagen 15: Disciplinas a las que hacen referencia las publicaciones sobre deporte femenino en Mundo Deportivo}

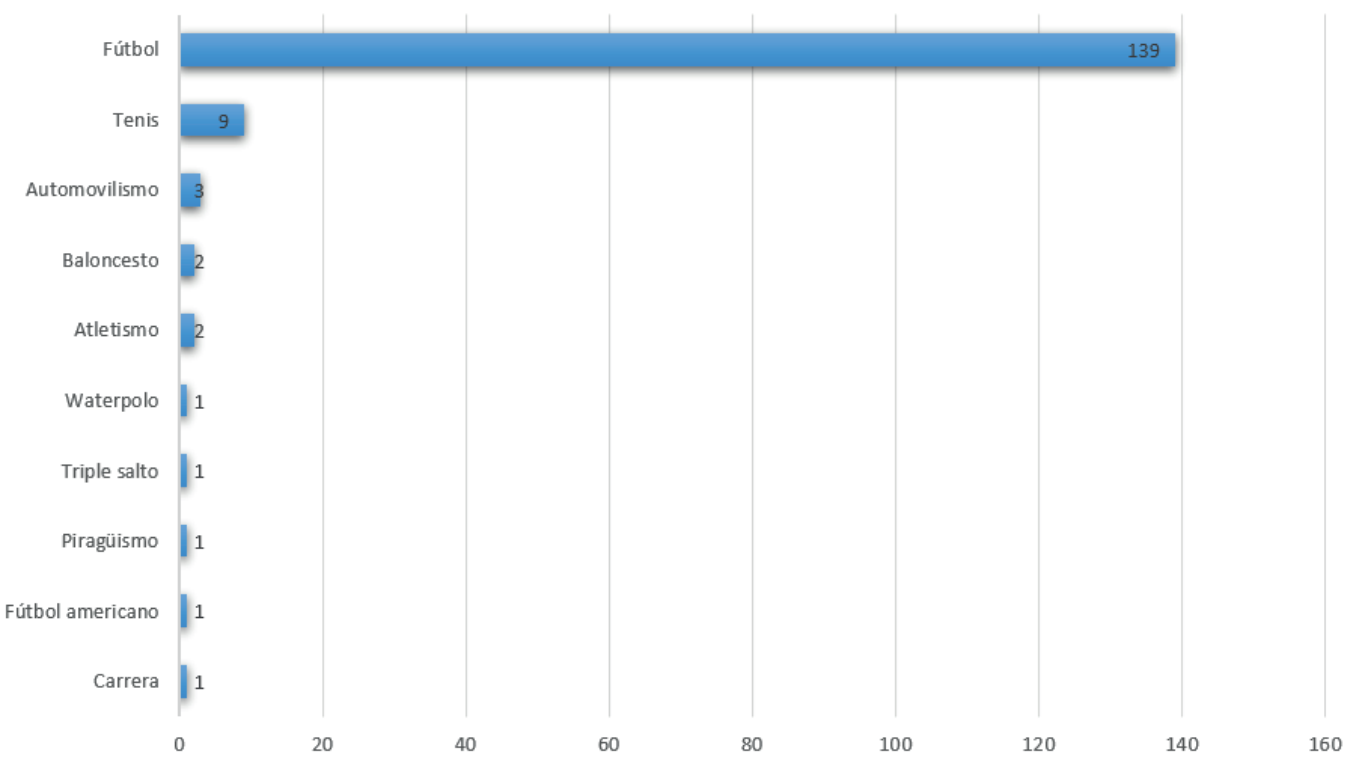

Fuente: Instagram / Elaboración propia 
Al tratarse también de un medio nacional, el área de referencia de Mundo Deportivo se vincula al deporte femenino español y a las deportistas nacionales. Es más, tan solo en el $14,11 \%$ de las publicaciones sobre deporte femenino, las protagonistas son deportistas extranjeras, sin vinculación a ningún club español, ofreciendo por lo tanto una perspectiva amplísima del ámbito deportivo femenino nacional, debido en gran parte a la gran atención que este diario presta a la actualidad del Barcelona Femenino.

\section{Imagen 16: Área de referencia de las publicaciones sobre deporte femenino en Mundo Deportivo}

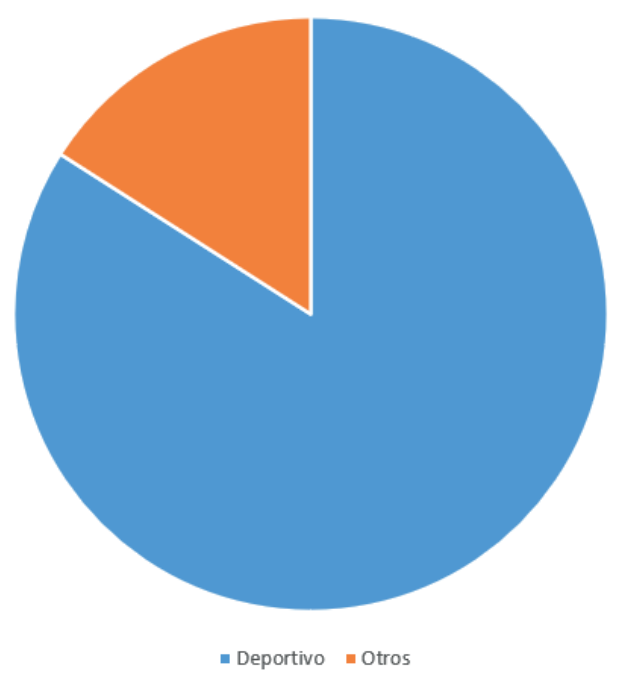

Fuente: Instagram / Elaboración propia

Por último, sobre el carácter de los post dedicados al deporte femenino publicados por Mundo Deportivo en el periodo analizado en Instagram, la mayor parte de ellos (un 84,05\%) se refieren a contenidos e informaciones meramente deportivos. Es más, en año y medio, este diario ha realizado once entrevistas (nueve a jugadoras del Barcelona, una a la tenista Carla Suárez y otra a la pilota de motos Laia Sanz). Eso sí, además de la actualidad deportiva, este diario cuenta también con otra serie de publicaciones (en menor cantidad) de contenido bastante variado: reportajes fotográficos, maternidades, reivindicaciones de derechos, enfermedades, vídeos virales...

\section{Imagen 17: Carácter de las publicaciones so- bre deporte femenino en Mundo Deportivo}

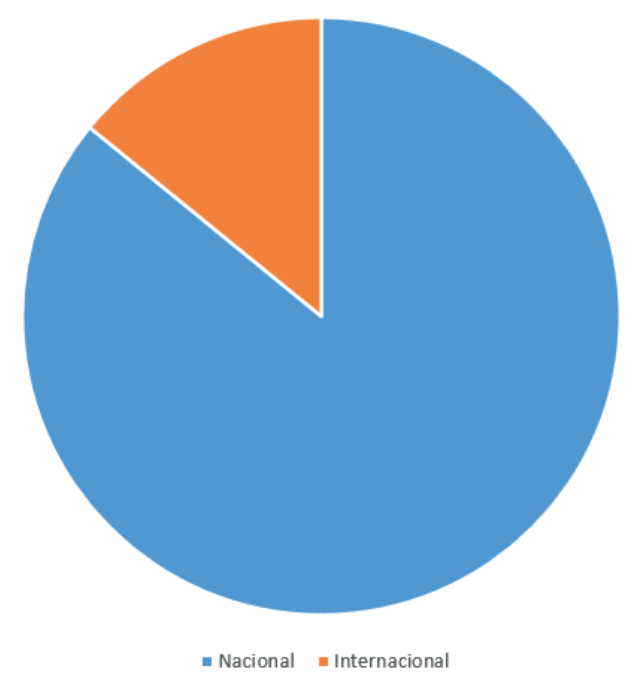

Fuente: Instagram / Elaboración propia

\subsection{Sport}

El diario Sport es el más reciente de todos en este análisis. Nació en 1979, tiene su sede en Barcelona y pertenece al grupo Zeta. Desde su aparición, este medio apostó por una "importante innovación tecnológica, se trataba del primer diario español con paginación a color, y en un formato inusual que ha conservado y ha marcado su personalidad" (Alcoba López 1999: 72). Asimismo, desde sus inicios, sport "marcó una línea editorial barcelonista y junto a la información siempre había opinión", decantándose además por "un formato pequeño" y convirtiéndose en "el primer diario deportivo que apostó por el impacto visual de las fotografías a color y también el primero en salir todos los días de la semana en color" (Sainz de Baranda Andújar 2014, 113).

En su afán por "adaptarse al gran crecimiento de las nuevas tecnologías" (García Noé 2016, 22), sport fue el primero de estos cuatro medios en llegar a Instagram; concretamente, el 1 de octubre de 2012. Tras el primer semestre de 2021, la cuenta oficial de este medio contabiliza 1.400.000 seguidores.

Entre el 01 de enero de 2020 y el 30 de junio de 2021, el diario Sport publicó un total de 3.598 post en Instagram, haciendo referencia 113 de ellos a las mujeres y al deporte femenino, es decir, un 3,14\% del total. Como se observa en la Imagen 19, este tipo de publicaciones tuvo su mayor pico en mayo de 2021, al igual que Mundo Deportivo, en base al triplete logrado por el FC Barcelona Femenino. 


\section{Imagen 18: Publicaciones de Sport en Instagram que involucran a mujeres y hombres durante el periodo analizado}

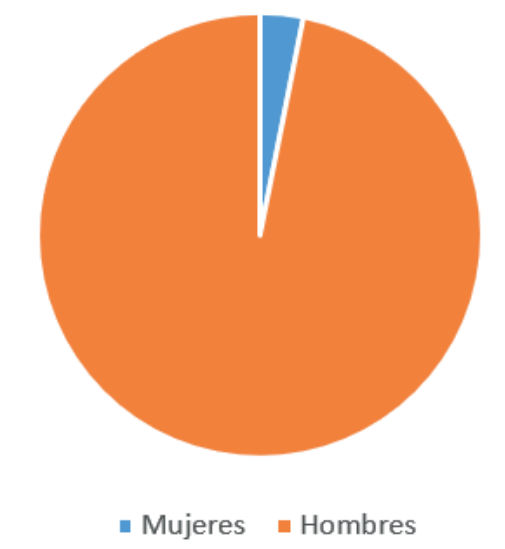

Fuente: Instagram / Elaboración propia

Imagen 19: Reparto de publicaciones en Instagram sobre deporte femenino por fecha en Sport

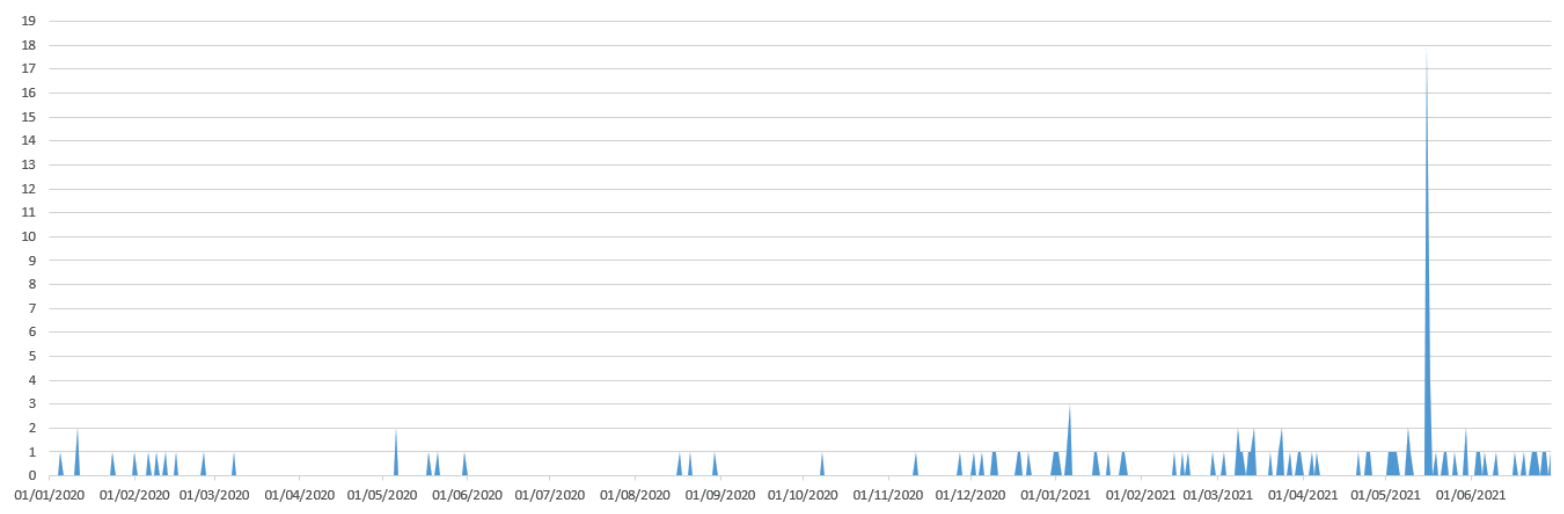

Fuente: Instagram / Elaboración propia

Al igual que Mundo Deportivo, el diario Sport tiene su sede en Barcelona, por lo que sus noticias prestan también especial atención al deporte catalán y, sobre todo, al fútbol y a la actualidad del FC Barcelona. De ahí que, distinguiendo por disciplinas, tan solo el 7,08\% de las publicaciones sobre deporte femenino analizadas hacen referencia a un deporte que no fuese el fútbol.

Asimismo, de las 105 publicaciones sobre fútbol femenino en el Instagram del diario Sport (de un total de 113), 96 hacen referencia al Barcelona Femenino, presuponiendo que la tendencia habitual se ha visto incrementada debido a los éxitos de las barcelonistas durante la temporada 2020-21. 


\section{Imagen 20: Disciplinas a las que hacen referencia las publicaciones sobre deporte femenino en Sport}

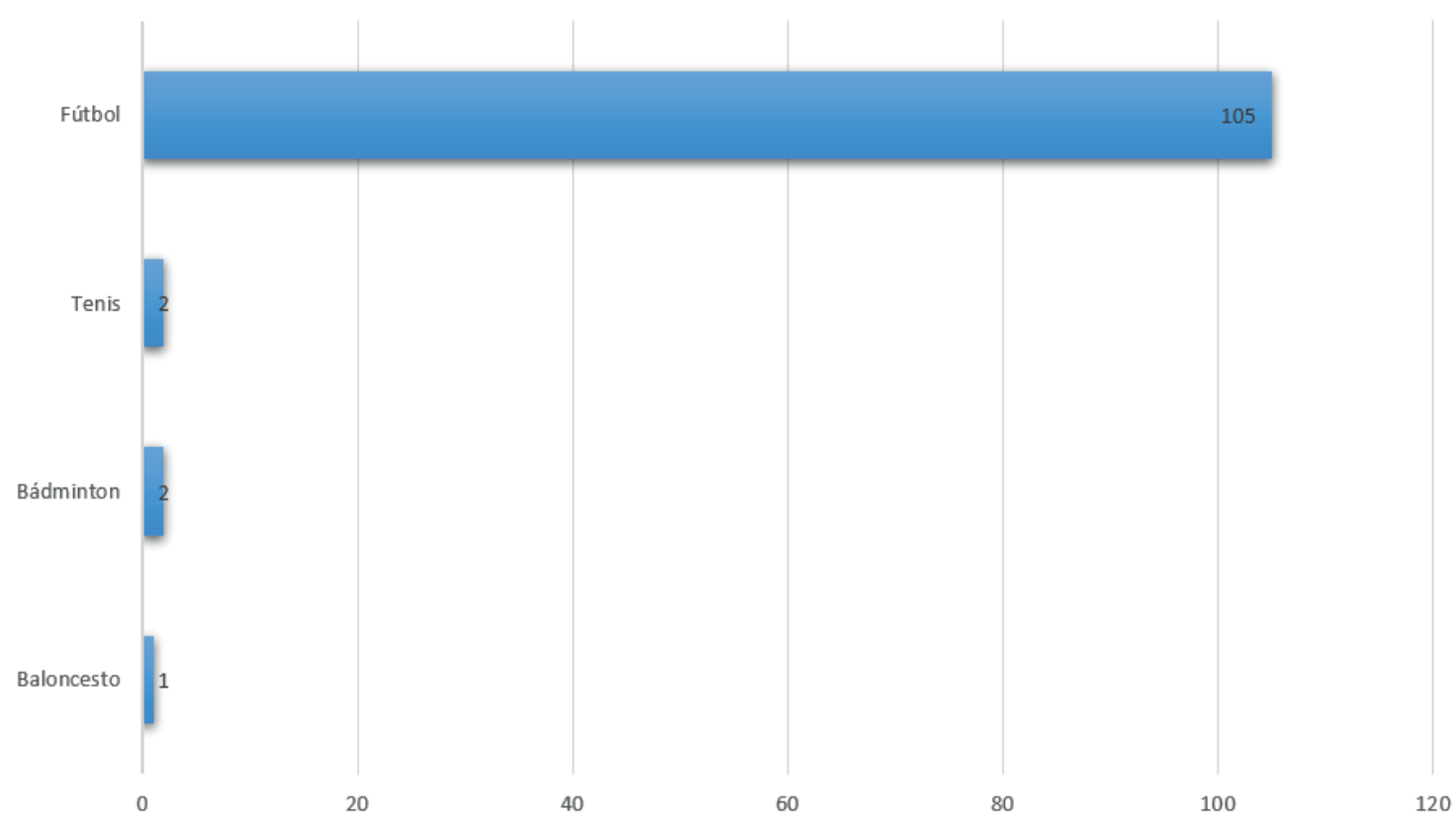

Fuente: Instagram / Elaboración propia

Al igual que en los casos anteriores, al ser sport otro medio nacional, su área de referencia se vincula al deporte femenino español y a las mujeres deportistas de nuestro país. Por ello, tan solo en el $5,31 \%$ de las publicaciones de sobre deporte femenino, las protagonistas son deportistas extranjeras, sin vinculación a ninguna entidad española. Además, al igual que ocurre con Mundo Deportivo, este diario ofrece una amplia perspectiva del ámbito deportivo femenino nacional al prestar gran parte de su atención a la actualidad de la sección femenina del Barcelona.

\section{Imagen 21: Área de referencia de las publicaciones sobre deporte femenino en Sport}

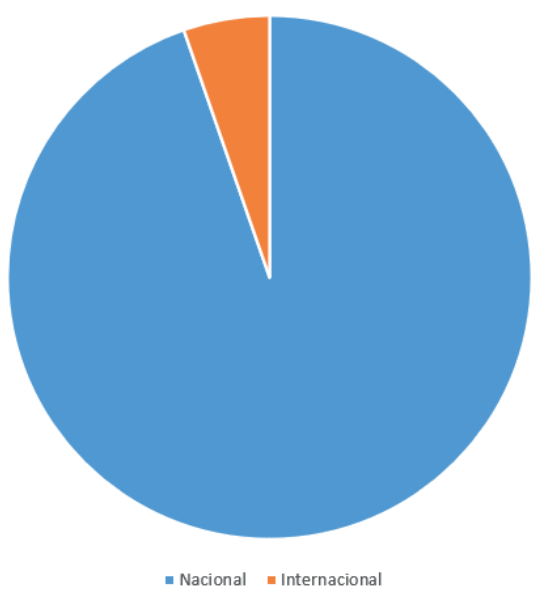

Fuente: Instagram / Elaboración propia 
Por último, el carácter del 91,15\% de las publicaciones de Instagram de Sport sobre deporte femenino en el periodo analizado es meramente informativo. Sin embargo, este diario muestra tan solo un total de cinco entrevistas a mujeres en año y medio (cuatro jugadoras del Barça y la tenista Carla Suárez). Aparte de la actualidad deportiva, otros asuntos que trata también sport (en menor cantidad) al referirse al deporte femenino son enfermedades, maternidades, entregas de premios...

\section{Imagen 22: Carácter de las publicaciones so- bre deporte femenino en Sport}

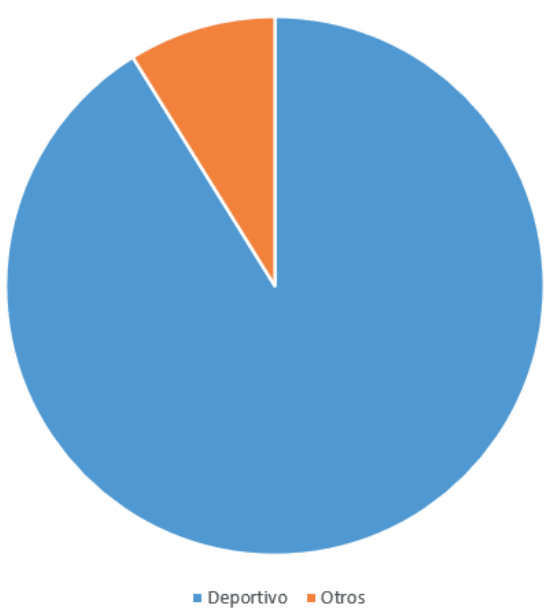

Fuente: Instagram / Elaboración propia

\section{Conclusiones}

Con esta investigación se ha pretendido abordar un novedoso tema de estudio que ha sido tratado de forma escasa, la imagen del deporte femenino y de las mujeres que los medios deportivos seleccionados (Marca, As, Mundo Deportivo y Sport) emiten en Instagram. Esta plataforma sirve de gran ayuda al periodismo, habiendo contribuido a iniciar "una era de redes de información mundial" (Navarro Zamora $2011,51)$ siendo "una buena posibilidad para ofrecer noticias, crónicas, previas... desde las cuentas periodísticas" (Panal Prior 2017, 4).

Como ya se comentó anteriormente, se han identificado un total de 471 unidades de análisis (post dedicados al deporte femenino), estudiando de ellas diferentes variables, de entre las 24.586 publicaciones emitidas por estos cuatro medios en Instagram entre enero de 2020 y junio de 2021. Esta escasez de contenidos (1,92\% del total) en los que las mujeres copan el protagonismo ya denota una imagen relegada de las mismas. Si bien es cierto que, conforme han avanzado los años, el deporte femenino goza de una mayor consideración, aún resta por un enorme trabajo y esfuerzo por lograr la equidad informativa en este ámbito, pues en estudios como el presente queda demostrado que, aunque el deporte femenino es tenido en cuenta por parte de los medios de comunicación, su frecuencia continúa siendo esporádica. Se extrae por tanto la afirmación de que, en las cuentas de Instagram de los cuatro medios analizados, la mujer no disfruta del mismo protagonismo que en hombre.

Como datos a tener en cuenta, As es el diario que más actividad presente en Instagram (9.664 publicaciones en año y medio), aunque es también el que menor número de post ha dedicado al deporte femenino (65). Por su parte, Sport es el que menor número de publicaciones ha emitido en el periodos estudiado, aunque es Mundo Deportivo quien registra "Ios mejores" resultados de entre los cuatro diarios. Así, este medio es el que más post que involucran a mujeres muestra (163), siendo también el que registra un mayor porcentaje de publicaciones de deporte femenino sobre el total (el 3,9\% en año y medio).

Asimismo, a través de un análisis cuantitativo de diferentes variables aplicables a aquellas publicaciones que involucran la participación femenina en los medios deportivos y periodo temporal en cuestión, se determinan las siguientes afirmaciones.

Los diarios con sede en Barcelona, Mundo Deportivo y Sport, muestran un mayor porcentaje de publicaciones relacionadas con el fútbol femenino (85,28\% y $92,92 \%$, respectivamente) debido a que sus contenidos giran en torno al FC Barcelona. Por su parte, Marca y As (con sede en Madrid) presentan publicaciones con deportes de distinta índole, mostrando una mayor variabilidad de disciplinas, aunque el fútbol continúa copando un lugar importante. Así, el $70,77 \%$ de post de Marca sobre deporte femenino hacen referencia a 23 disciplinas diferentes al fútbol: atletismo, automovilismo, bádminton, baloncesto, boxeo, fitness, gimnasia, golf, halterofilia, kárate, natación, pádel, pentatlón, relevo, running, skateboard, snowboard, tenis, triatlón, triple salto, vóley playa, waterpolo y yoga. Mientras que en As, el 61,53\% de sus contenidos se refiere a deportes diferentes al fútbol como; en concreto a otros 15: atletismo, bádminton, baloncesto, béisbol, bolos, boxeo, comba, crossfit, gimnasia, golf, natación, salto de altura, tenis, tiro con arco y waterpolo.

Los cuatro medios analizados abarcan un ámbito nacional; sin embargo, unos más que otros dedican un porcentaje considerable a deportistas extranjeras. Así, As, que es el diario que más publicaciones ha 
emitido sobre deporte femenino, es el que más atención presta a lo que ocurre fuera de nuestras fronteras. Por el contrario, sport es quien mayor porcentaje dedica al ámbito nacional, teniendo en cuenta que una gran parte de sus contenidos hacen referencia al FC Barcelona.

No obstante, una de las variables o atributos más a tener en cuenta es el carácter de estos post sobre deporte femenino; es decir, el rol que ocupan las mujeres que lo protagonizan. En este caso, tanto Mundo Deportivo como Sport destacan por dedicar un $85,05 \%$ y un $91,15 \%$ de sus contenidos, respectivamente, a informaciones de carácter meramente deportivas. Mientras, Ios porcentajes de Marca y As (57,69\% y $44,62 \%$, respectivamente, sobre contenidos de carácter deportivo) dan muestras de que, en comparación con la prensa catalana antes citada, la imagen de la mujer va más orientada a temáticas de entretenimiento (contenidos virales, sobre todo vídeos).

Analizadas las publicaciones sobre deporte femenino en Instagram de estos medios en el espacio temporal especificado, cabe añadir que la presente investigación ha obviado las estadísticas relativas al número de "me gusta" y comentarios de cada post, siendo estos parámetros una limitación para el estudio teniendo en cuenta que sus cifras varían constantemente y no se queda establecido como algo fijo e invariable (De la Rosa Mendoza 2018, 32).

Expuestas estas conclusiones, conviene tener en consideración una serie de recomendaciones, tal y como muestra la autora Bohórquez León $(2020,87)$ para que la mujer abandone el rol de figura de entretenimiento en los medios y sea valorada de forma merecida como deportista, aprovechando fehacientemente la dimensión que internet le ha otorgado al periodismo deportivo y a los profesionales de la información, que han pasado a contar con una amplia variedad de posibilidades y oportunidades para "llegar a cualquier parte del mundo de manera instantánea, crear nuevas formas de hacer periodismo y cambiar la visión del negocio existente y forjada a través de los años" (Codonyer Canet 2016, 15).

Una de ellas sería fomentar la visibilización de la mujer deportistas desde el inicio de su trayectoria y mostrar una imparcialidad hacia las mismas, brindándoles un trato igualitario de oportunidades a las deportistas de todas las disciplinas, como el que se le da a los hombres, por medio de una mayor frecuencia de publicaciones sobre ellas que estén enfocadas exclusivamente al ámbito deportivo.

También se podría promocionar el contenido de diversas actividades deportivas realizadas por mujeres con el objetivo de propagar y difundir su existencia, de manera que la audiencia tenga conocimiento de ellas y se fomente la promoción e incentivación de la igualdad de género, no necesariamente en el deporte, sino en todos los ámbitos,

Y, por supuesto, sería recomendable que con el paso del tiempo abunden investigaciones de este tipo, relacionadas con la imagen de la mujer en los medios deportivos, dado que actualmente no existe una gran variedad de trabajos al respecto, lo cual dificulta la visibilización e igualdad de la mujer en el deporte.

\section{Referencias}

Adá Lameiras, Alba. 2019. "Invisibilización de la mujer deportista en el twitter de los medios deportivos". Comunicación Y Género 2 (1): 33-46. https://doi. org/10.5209/cgen.64460

Alcoba López, Antonio. 1999. La prensa deportiva: tratamiento inédito sobre el género específico del deporte, y cómo hacer una publicación deportiva ideal. Madrid, España: Instituto Universitario Olímpico de Ciencias del Deporte.

Alfaro Gandarillas, Elida, Mercedes Bengoechea Bartolomé y Benilde Vázquez Gómez. 2010. Hablamos de deporte: En femenino y en masculino. Madrid, España: Instituto de la Mujer (Ministerio de Sanidad, Política Social e Igualdad). https://www.inmujeres.gob. es/areasTematicas/AreaDeporte/docs/MaterialesDidacticos/HablamosDeporte.pdf

Bohórquez León, Liliana del Rocío. 2020. La imagen de la mujer difundida en los medios de comunicación deportivos digitales. Análisis de contenido del medio digital Deportivo en la red social Instagram [Trabajo Final de Grado]. Guayaquil, Ecuador: Universidad Católica de Santiago de Guayaquil. http://repositorio.ucsg.edu.ec/handle/3317/15071

Carretero, Rodrigo. 2014. "Instagram, una herramienta al servicio del periodismo". Media-tics. 02 de Septiembre. https://www.media-tics.com/ noticia/2301/medios-de-comunicacion/instagram-una-herramienta-al-servicio-del-periodismo. html

Codonyer Canet, Víctor. 2016. El uso estratégico de Twitter en el periodismo deportivo. El caso valenciano de Pedro Morata, Julio Insa, Nacho Cotino, Manolo Montalt y Jordi Gosálvez [Trabajo Final de Grado]. Castellón de la Plana, España: Universitat Jaume I. http://hdl.handle.net/10234/163900

De la Rosa Mendoza, Raquel. 2018. El uso de Instagram en los diarios deportivos españoles. Los casos de As, Marca, Mundo Deportivo y Sport [Trabajo Final de Grado]. Valladolid, España: Universidad de Valladolid. https://uvadoc.uva.es/handle/10324/33101 
Dunning, E. (2003): El fenómeno deportivo. Estudios sociológicos en torno al deporte, la violencia y la civilización. Barcelona, España: Paidotribo.

Fernández Carretero, David. 2018. Mujer y deporte: Análisis del seguimiento informativo de las recomendaciones del Consejo Superior de Deportes en los telediarios de TVE1 [Trabajo Final de Grado]. Sevilla, España: Universidad de Sevilla. https://idus.us.es/ handle/11441/79054

Fraga Medín, Cristina A. 2007. Las mujeres y los medios de comunicación. Una relación controvertida. Comunicación e cidadanía. Revista internacional de xornalismo social (1): 45-52. https://dialnet.unirioja. es/servlet/articulo?codigo $=2542840$

García Noé, Judith. 2016. Estudio de la parcialidad en la prensa deportiva española: Los casos de AS, MARCA, Mundo Deportivo y SPORT [Trabajo Final de Grado]. Barcelona, España: Universitat Autònoma de Barcelona. https://ddd.uab.cat/record/169395

Gonzáles Pagés, Julio César y Daniel Alejandro Fernández González. 2009. "Masculinidad y violencia: aproximaciones desde el universo del deporte". Educar em revista (35): 123-136. https://doi.org/10.1590/ s0104-40602009000300010

Lavalle, Alejandro Martín. 2017. De Bajtin al Smartphone: Instagram ¿una nueva topología espectacular? Buenos Aires, Argentina: Universidad de Buenos Aires.

Layton, Mathías Joaquín. 2020. Evolución e importancia de las redes sociales en el fútbol femenino tinerfeño [Trabajo Final de Grado]. Tenerife, España: Universidad de La Laguna. https://riull.ull.es/xmlui/ handle/915/21393

Lirola Pino, Candela, Raquel Martín Perales y Elena Martín Pueyo. 2015. Nuevas vías para la publicidad : análisis de la red social Instagram [Trabajo Final de Grado]. Sevilla, España: Universidad de Sevilla. https://idus.us.es/handle/11441/26088

López Albalá, Elena. 2016. "Mujeres deportistas españolas: Estereotipos de género en los medios de comunicación". Sociologiados. Revista de Investigación Social 1 (2): 87-110. http://dx.doi.org/10.14198/ socdos.2016.1.2.04

López Díez, Pilar. 2011. Deporte, mujeres y medios de Comunicación. Sugerencias y recomendaciones. Madrid, España: Consejo Superior de Deportes.

Morales, Paula. 2021. "Instagram, las cifras imprescindibles para el 2021". Digimind. 10 de Marzo. https://blog.digimind.com/es/insight-driven-marketing/instagram-cifras-imprescindibles-2021

Navarro Zamora, Lizy. 2011. "Orígenes del ciberperiodismo". Correspondencias \& Análisis (1): 49-64. https://doi.org/10.24265/cian.2011.n1.04

Panal Prior, Antonio. 2017. El uso de Instagram en los medios de comunicación deportivos. Análisis de Bleacher Report, L'Équipe y Marca [Trabajo Final de Grado]. Sevilla, España: Universidad de Sevilla. https://idus.us.es/handle/11441/64503

Romero de la Marta, Adrián. 2019. El auge del deporte femenino y su repercusión en los medios de comunicación [Trabajo Final de Grado]. Sevilla, España: Universidad de Sevilla. https://idus.us.es/handle/11441/91422

Sainz de Baranda Andújar, Clara. 2013. Mujeres y deporte en los medios de comunicación. Estudio de la prensa deportiva española (1979-2010) [Tesis doctoral]. Madrid, España: Universidad Carlos III de Madrid. https://e-archivo.uc3m.es/handle/10016/16505

Sainz de Baranda Andújar, Clara. 2014. "Prensa deportiva nacional y regional en España". Historia Y Comunicación Social 19: 107-118. https://doi. org/10.5209/rev_HICS.2014.v19.45014

Sontag, Susan. (1977). Sobre la fotografía. México DF, México: Alfaguara.

Toffoletti, Kim y Holly Thorpe (2018). "Female athletes' self-representation on social media: A feminist analysis of neoliberal marketing strategies in "economies of visibility" . Feminism \& Psychology 28 (1): 11-31. https://doi. org/10.1177/0959353517726705 